InterAção | 97

\title{
A PROFISSÃO DE FÉ NO REINO VISIGODO: UM ESTUDO COMPARADO SOBRE OS FLAVIUS VISIGODOS, RECAREDO E RECESVINTO
}

\author{
Rodrigo dos Santos Rainha - Mestre - PPGHC/UFRJ ${ }^{1}$ \\ Orientadora: Leila Rodrigues da Silva
}

Os séculos VI e VII são marcados pelo estabelecimento da transação entre as elites episcopais, principais representantes das populações hispano-romanas, e visigodas, que então governavam a maior parte dos territórios na península Hispânica.

Neste texto, sublinharemos dois momentos em que a relação de aproximação entre esses grupos fica evidenciada - quando acontecem as reuniões conciliares, especialmente aquelas em que suas atas são marcadas pelo discurso do monarca em sua introdução, prática que podemos identificar, por exemplo, nas atas do III e VIII Concílios de Toledo.

Nossa comunicação, então, visa identificar semelhanças e diferenças no processo de ascensão ao poder dos reis indicados, nas atas anteriormente mencionadas, como os autores dos discursos: Flavius Recaredo e Flavius Recesvinto. Os dois monarcas têm em comum o fato de serem filhos de governantes que enfrentaram grande oposição por parte de setores o episcopado - no caso Leovigildo e Chindasvinto, respectivamente -, assumiram o trono de maneira hereditária e

1 Temática deste artigo foi apresentada originalmente na VII Semana de Estudos Medievais, e foi revisto e reformulado para este artigo. 
98 | InterAção

direcionaram suas políticas no sentido de constituir uma aliança entre episcopado e monarquia.

\section{Apresentação}

A preocupação em relacionar eventos políticos e religiosos nas pesquisas de História é um aspecto que embora não seja novo, continua sendo de vital importância para a Nova História Politica. ${ }^{2}$ E este é o prisma trazido para análise da relação entre a monarquia e o episcopado no reino visigodo. $\mathrm{O}$ que apresento nessa comunicação é apenas uma das possibilidades. Para esse entendimento no caso visigodo, elegemos dois reis e suas participações em duas das principais reuniões conciliares de todo o reino, o III e o VIII Concílios de Toledo.

Em minha dissertação de mestrado, recém-defendida e aprovada em junho passado pelo Programa de Pós-graduação em História Comparada, ${ }^{3}$ enfatizei as relações entre o poder e a educação, e sua difusão por parte do episcopado visigodo durante o século VII. Essa pesquisa está vinculada ao Programa de Estudos Medievais, orientada pela professora Leila Rodrigues da Silva. Em nossa dissertação, continuamente chamou a atenção o imbricamento entre o campo religioso e politico. ${ }^{4}$ Por um lado, a linguagem se manifesta, mesmo

2 Cf.: COUTROT, A. Religião e Política. In: REMOND, R. Para uma História Política. Rio de Janeiro: UFRJ, 1998.

3 Cf.: RAINHA, R. S. A Educação no Reino Visigodo: as relações de poder e o epistolário do bispo Bráulio de Saragoça. Rio de Janeiro: HP Comunicações, 2007.

4 Cf.: BOURDIEU, P. Gênese e Estrutura do Campo Religioso. A Economia das Trocas Simbólicas. São Paulo: Perspectiva, 2003. 
InterAção | 99

por monarcas, que assumiam ares sacerdotais, por outro, questões de administração, patrimônio, lei e diplomacia se faziam presentes em áreas que, teoricamente, os elementos a serem abordados deveriam ser teológicos.

A partir dessa reflexão, decidimos construir essa comunicação de modo que o entendimento da relação entre monarquia e episcopado no reino visigodo ficasse mais visível. Para tal, compararemos os discursos dos reis Recaredo, considerado pela historiografia ${ }^{5}$ como responsável pela aliança entre a igreja seguidora da ortodoxia nicena e a monarquia visigoda no ano de 589; e Recesvinto, um dos monarcas de mais longo reinado à frente dos visigodos e tratado ${ }^{6}$ como legislador de maior relevância, na abertura dos Concílios III e VIII de Toledo.

\section{Problema}

A presença dos visigodos na Península Ibérica é ampliada e fixada após a batalha de Voulé, mas sua relação com as populações romanas já podiam ser observadas anteriormente. Essa convivência tem como uma de suas principais características a identificação dos visigodos com diversos elementos romanos, como a religião cristã, ainda que ariana, sua administração e reconhecimento da língua latina.

Durante seu estabelecimento, observaram-se no grupo guer-

5 Cf.: GARCIA MORENO, Luis A. Historia de España Visigoda. Madrid: Cátedra, 1989; ORLANDIS, J. História Del Reino Visigodo Español. Madrid: Rialp, 1990.

6 Cf.: GARCIA MORENO. Op. cit. p. 280-353. 
100 | InterAção

reiro que suas principais relações, marcadamente pessoais, se estabeleciam na tradição e nos chefes militares, Estes, utilizaram-se dessas diferenças como forma de afirmação e distinção das populações locais, em superioridade numérica. ${ }^{7}$

Segundo Santiago Castellanos ${ }^{8}$, o amadurecimento dessas relações no século VI, assim como a gradual aproximação das elites hispano-romanas, trouxe a necessidade de politicamente modificar o processo autônomo dos chefes militares, fortalecendo a ideia de constituição de um regnum. ${ }^{9}$

Durante esse mesmo estabelecimento do reino visigodo, pode-se notar uma população hispano-romana, em primeiro momento, órfã das antigas lideranças e necessitando de um elo que as unisse, ou ao menos as representasse - apresenta-se o papel da igreja de inspiração romana. Esse grupo religioso busca sua legitimidade nos padrões da romanidade, fortalecendo seus quadros e aproximando de seus espaços privilegiados os membros da elite local.

Assim, os grupos da aristocracia visigoda, no intuito de constituir seu reino, estabeleceram questões jurídicas como a proibição de

7 Cf.: VELASQUEZ SORIANO, Isabel. Âmbitos y ambientes de la cultura escrita em Hispania (s. VI): De Martín de Braga a Leandro de Sevilla. Studia Ephemeridis Augustinianum, Roma, n. 46, p. 329-351, 1994.

8 Cf.: SANTIAGO CASTELLANOS. La Hagiografia Visigoda. Dominio social y proycción cultural. Logroño: Fundación San Millán de la Cogolla, 2004. p. 163 - 302.

9 Cf.: FRIGHETTO, R. A imagem do rei nas fontes hispano-visigodas: aspectos teóricos. In: Anais da XXI Reunião da Sociedade Brasileira de Pesquisa Histórica. Curitiba, p. 81-96, 2002; _ . 0 problema da legitimidade e a limitação do poder régio na Hispania visigoda: o reinado de Ervígio (680-687). Gerión, Madrid, v. 22, n. 1. p. 421 $-435,2004$. 
InterAção | 101

casamentos mistos, entre godos e hispano-romanos, ${ }^{10}$ além dos direitos sobre as terras serem aproximados e determinados. Leovigildo, o então monarca, como principal arquiteto dessa transformação, busca o mesmo processo em relação à religião, e nesse momento dois grupos entram em conflito: os ortodoxos, seguidores da Igreja romana e dos Concílios de Nicéia e Calcedônia, e os Arianos, discípulos de Ário e elo integrador entre a nobreza visigoda.

No processo deflagrado por Leovigildo o centro de suas discussões é o fortalecimento das "instituições" que poderia constituir um status de reino. Neste sentido o apoio ao arianismo, como estrutura representativa de toda aristocracia dos visigodos em termos religiosos, tornam-se a opção do monarca na tentativa de unificação religiosa. Mas sem apoio de outros importantes grupos locais, enfrenta uma revolta liderada pelo próprio filho, com justificativa de uma unificação religiosa pela via ortodoxa. ${ }^{11}$ Leovigildo vence a batalha, mas não consegue dar prosseguimento a seu projeto político.

Mas a força do rei garante a ascensão de seu outro filho ao trono, Recaredo. Aproximando-se da Igreja ortodoxa, ele dá continuidade, com sucesso, ao empreendimento de seu pai. E é nesse processo que, em 589, o rei Recaredo abre a seção do III Concílio de Toledo, e ainda, ao seu final, segue um édito, o que dá à reunião eclesiástica, peso de lei. Serão esses os elementos que utilizaremos para comparar a profissão de Recaredo, que assumindo uma clara romani-

10 Cf.: THOMPSON, E. A. Los Godos en España. Madrid: Alianza, 1971. p. 299-342. 11 Cf.: ANDRADE FILHO, Ruy de Oliveira. A Tirania de Um Santo na Antiguidade Tardia (século VI). In: I Simpósio de sobre História das Religiões. Assis, 1999. Disponibilizado: http://members.tripod.com/bmgil/ afro20.htm. (acessado em 08/06/2007). 
102 | InterAção

dade, adota Flavius como título em sua firma conciliar.

Se a aliança entre monarca e Igreja fortalece a presença de um reino em si, em que o cargo máximo é inquestionável (uma vez que era legitimada por Deus), a posição do rei passa a ser o objetivo máximo das diversas correntes ou grupos da nobreza visigoda.

No princípio do século VII, a primeira prova desse novo momento é o assassinato do filho de Recaredo, rompendo com a sucessão hereditária e dando início a uma série de golpes. Em toda primeira metade do século VII, os golpes sucederam-se. Observa-se que apenas Sisebuto e Chindasvinto têm transições em paz e hereditárias. ${ }^{12}$

Nesse momento de instabilidade, a Igreja visigoda, fortalecida como legitimadora e apresentando uma estabilidade frente à convulsão política, experimenta um incremento de seu poder, aumentando de forma substancial sua produção intelectual e sua influência junto ao monarca. Isso se pode observar nos IV, V e VI Concílios de Toledo, convocados por monarcas que recém-ascenderam ao poder e buscaram legitimidade nas deliberações conciliares.

Essa aliança experimenta uma parcial ruptura quando da ascensão de um chefe militar chamado Chindasvinto. Considerado por parte do episcopado como rude, tirano, velho ${ }^{13}$, esse monarca busca fortalecer o poder real - elimina candidatos ao trono, assassina parte da nobreza palaciana, desapropria terras eclesiásticas, nomeia bispos

12 Cf.: ORLANDIS, J. Op. cit. p. $316-370$.

13 É importante sublinhar que Chindasvinto é um chefe militar de idade avançada e teria, segundos fontes conciliares, em torno de 80 anos. Cf.: Concílios Visigoticos e Hispano-Romanos. Jose Vives. (Ed.) Madrid: CSIC. Instituto Enrique Florez, 1963. X Concílio de Toledo. 
InterAção | 103

contra a vontade do episcopado, modifica leis, abre frentes de batalha. Essas atitudes atribuídas ao rei revelam-nos sua principal preocupação: o fortalecimento do seu próprio poder. ${ }^{14}$

Durante seu governo, parte da Igreja busca uma aproximação, sugerindo que Chindasvinto abandonasse o trono em favor de seu fi1ho. ${ }^{15}$ Segundo as alegações presentes na carta assinada por uma série de clérigos e um nobre da região de Saragoça, essa atitude evitaria disputas por sucessão. Além do mais novo ser mais capaz de guerrear, tinha como principais características, segundo Bráulio de Saragoça, a serenidade e a clemência, principalmente por ter sido educado pela Igreja. $^{16}$

Chindasvinto primeiro associa seu filho ao trono, ${ }^{17} \mathrm{e}$ no VIII Concílio de Toledo comemora sua ascensão ao trono após a morte de seu pai. Nesta comunicação abordaremos justamente a profissão de fé nessa reunião, em que ele é a chamado a ser o monarca, sem divisão, com a recente vontade do pai.

\section{Comparação}

A partir desse quadro, nossa hipótese é que ao compararmos as profissões de fé de Recaredo e Recesvinto, apesar da distância tem-

14 Cf.: Concilios. Op. cit. e Lynch, C. H. e GALINDO, P. San Braulio 0 bispo de Zaragoza (631 - 651): Su vida y sus obras. Madrid: Instituto Enrique Florez, 1950.

15 Cf. RAINHA, R. S. Op. cit. $61-89$.

16 Idem.

17 Cf.: FRIGUETO, R. Cultura e Poder na Antigüidade Tardia Ocidental. São Paulo: ABDR, 2000. 
104 | InterAção

poral, temos dois marcos que servem como elementos de renovação da aliança entre monarquia e episcopado, mas sem, no entanto, romperem os processos políticos iniciados por seus antecessores.

O Concílio ocorrido em 653 é uma reafirmação da aliança de 589, transformada pelas características do reino, mas que em nenhum momento estivesse sido inteiramente rompida.

A escolha dos dois monarcas para esse tema pode ser entendida por alguns elementos em comum: a sucessão hereditária e advinda de reis contestados; a adoção do nome Flavius, que tem característica de título e é uma retomada romana; ambas as assembléias terem especialmente sublinhado seu peso de lei e reafirmação da aliança entre monarca e episcopado.

Elegendo alguns eixos como forma de comparar os discursos de ambos nos Concílios que analisamos: a participação na abertura desses Concílios, a erudição, a leitura dos monarcas sobre a fé, o que é entendido como obrigação da igreja, o que é papel do monarca na aliança e o papel político de seus discursos.

A abertura do termo conciliar é feita e dominada por Leandro de Sevilha. Nessa fase, é dada voz a Recaredo, por três vezes, de forma explícita: a primeira, quando esle faz a abjuração do arianismo, seguindo os preceitos do Concílio de Nicéia; a segunda, quando abjura em nome de todos os nobres, seguindo o Concílio da Calcedônia; e a terceira, na confirmação de sua profissão de fé feita de forma breve. Em outras passagens, Leandro sublinha que todos seguiram a atitude do monarca em determinado gesto ou prática. ${ }^{18}$

18 Cf. Concílios... Op. cit. III Concílio de Toledo. 
InterAção | 105

Devemos sublinhar que em sua profissão de fé Flavius Recaredo, apesar da referência romana, não apresenta indicativos de profundo conhecedor dos elementos educacionais, pois seus gestos e práticas são direcionados e repetem um padrão.

O mesmo não se pode afirmar do posicionamento de Recesvinto no VIII Concílio. De forma assegurar seu domínio da reunião, assim como seu discurso, o redator das atas escreve que "serão transcritas as palavras do Sereníssimo rei Recesvinto”.

Como já indicado, esse monarca fora educado no seio da Igreja. Tinha uma relação especial com diversos membros do episcopado, solicitando inclusive a um desses que organizasse o código jurídico, obra que marca o seu governo. ${ }^{19}$ Sua profissão de fé tem seis páginas, e na sua firma, além de reproduzir o padrão, "firmo com as próprias mãos, ${ }^{20}$ faz questão de sinalizar que concordava e o fazia após expor suas ideias e sua vontade.

A questão do entendimento da religião por parte dos monarcas é o que podemos realçar como foco do primeiro Concílio. A negação de todo e quaisquer elementos arianos, em especial o posicionamento da trindade, indica que sob esta estaria o próprio rei.

Recaredo, além da abjuração que mencionamos e de acordo com o redator das atas, reconhece e obriga todos os que estavam em erro a ajoelharem-se e seguirem a verdadeira fé. $\mathrm{O}$ posicionamento como chefe dos godos e seu trato simbólico no reconhecimento da ortodoxia nicena é um marco para o estabelecimento da aliança entre 
106 | InterAção

monarca e episcopado no reino visigodo. ${ }^{21}$

A postura de Recesvinto sobre a questão da fé é mais tênue. Em seu discurso, reconhece a prevalência da Igreja católica e a unidade de seu credo, respeitando "sua regra verdadeira, santa e sincera que firmemente abraço a tradição apostólica e reconheço os concílios." $22 \mathrm{~A}$ posição de líder da Igreja, respeitador de seus clérigos não é um acaso - faz parte da postura assumida pelo rei, nos diversos concílios que este convoca, em que adota uma postura sacerdotal.

$\mathrm{O}$ arianismo não é sequer citado. Para o rei, a fé verdadeira é una, ou seja, a aliança estabelecida por Recaredo ainda é vigente, ainda que transformada e apresentando novos elementos.

$\mathrm{Na}$ construção de um pacto, que é em nossa comunicação a principal questão, temos uma via de mão dupla na qual os monarcas têm obrigações de protetores para a Igreja, entretanto o episcopado teve um cuidado especial na legitimação de seu rei. Seja em Recaredo ou em Recesvinto, identificamos essa relação:

1- Na profissão de fé do III Concílio de Toledo, a Igreja tem como função reconhecer e afirmar a tradição da estirpe visigoda, indicando que esta fora traída pela heresia de Ário e seus doutores. Analisando-os como pertencentes à ortodoxia nicena, após abjuração da heterodoxia, a Igreja reconhecia o papel e o direito do monarca em guiar os povos da Hispania. 2- Recesvinto proclama na sua profissão de fé que, 'por Deus

21 José Orlandis (0p. cit.) acredita que a unção fosse algo comum desde Recaredo, mas só teremos registro oficial desse fenômeno com o rei Wamba, no final do século VII.

22 Cf.: Concilios. 0p. cit. VIII Concílio de Toledo. 
e pela Igreja', aqueles que atentassem contra o monarca jamais mereceriam perdão e estariam condenados para sempre, jurídica e religiosamente. Nota-se um amadurecimento e imbricamento da aliança, na qual a função legitimadora se especializa. Ainda que não haja um relato oficial neste momento de unção régia, nesse Concílio, Recesvinto recebe a benção do episcopado para suas atitudes. ${ }^{23}$

Por parte dos reis, a obrigação não era menor. Recaredo sinaliza a obrigação de que todos os representantes da Igreja Ariana, assim como os nobres, e ele próprio, reconhecessem a verdade da fé católica publicamente. E mais que isso, em um édito real ao final do Concílio, dá peso de lei às decisões tomadas ali. Em outras palavras, é oferecida como contrapartida a prevalência católica no campo religioso.

$\mathrm{Na}$ metade do século VII, o posicionamento no campo religioso certamente não era mais o principal questionamento, e por isso a posição de Recesvinto é a de ser o defensor máximo da Igreja - papel no qual ele, de certa forma, se considera o representante máximo. Assim, o monarca afirma que todos os súditos do reino são, também, súditos da Igreja e a ela devem respeito e obediência, pois 'aquele que não o fizer sentirá o peso de sua autoridade real'.

A adoção do título-nome Flavius por Recesvinto e Recaredo é um aspecto relevante. A utilização do termo demonstra a clara busca pela afirmação de legitimidade no Império Romano. Apesar do ocidental neste momento já ser uma lembrança, sobrevive no imaginário como algo que é genuíno, e não à toa passará a ser buscado pelos

23 Idem. 
108 I InterAção

visigodos quando se afirma a ideia do estabelecimento do Regnum. ${ }^{24}$

Além disso, a presença do oriente, em especial durante o reinado de Recaredo, é um espelho para o fortalecimento e confirmação, em termos de política externa, da posição do próprio reino. E é nesse ponto que o episcopado é fundamental, e, provavelmente, a fonte de inspiração para esta confirmação.

A influência de Recesvinto para adoção do mesmo título, em nossa leitura, está diretamente vinculada a Recaredo, uma vez que este assume para os demais monarcas posição especial no ideário local. Em um projeto de reorganização do reino proposto por Recesvinto, aproximar-se de alguma forma de Recaredo seria uma forma de se autolegitimar.

\section{CONSIDERAÇÕES FINAIS}

Nesta comunicação exploramos a intensa relação estabelecida entre o episcopado e a monarquia no reino visigodo. Elegendo como marcos os III e VIII Concílios de Toledo, e procurando a voz dos monarcas nessas reuniões, identificamos como característica principal uma continuidade de processo. Significa dizer, que em ambos, de maneira diversa por seus contextos, tratam de alinhavar alianças em que tanto o rei necessitava do poder da Igreja, como o episcopado se escorava no poder do monarca para seu próprio fortalecimento. Com efeito, são membros da elite local legitimando-se mutuamente e criando um sistema em que política e religião tornam-se quase um

24 Cf.: FRIGHETTO, R. A imagem do ... 0p. cit. 
InterAção | 109

único campo.

O primeiro Concílio, no qual Flavius Recaredo é o expoente, estabelece as bases da aliança entre a Igreja e a monarquia proporcionando o estabelecimento de um regnum visigodo; o segundo, liderado por Flavius Recesvinto, busca ratificar, na continuidade da aliança, a concentração de poder obtida por seu pai, mas optando por uma via diplomática e tornando-se um rei sacerdote.

Para reforçar e aclarar as novas relações entre monarca e episcopado, em especial pelas novas conjunturas de uma nobreza de característica palaciana no princípio da segunda metade do século VII, o segundo escora-se nas atitudes do primeiro e da sua capacidade de arregimentar o episcopado em torno de si.

\section{REFERÊNCIAS}

Concilios Visigoticos e Hispano-Romanos. Jose Vives. (Ed.) Madrid: CSIC. Instituto Enrique Florez, 1963.

ANDRADE FILHO, Ruy de Oliveira. A Tirania de Um Santo na Antiguidade Tardia (século VI). In: I Simpósio de sobre História das Religiões. Assis, 1999. Disponibilizado: http://members.tripod.com/ bmgil/ afro20.htm. (acessado em 08/06/2007).

BOURDIEU, P. A Economia das Trocas Simbólicas. São Paulo: Perspectiva, 2003.

COUTROT, A. Religião e Política. In: REMOND, R. Para uma História Politica. Rio de Janeiro: UFRJ, 1998. 
110 | InterAção

FRIGHETTO, R. A imagem do rei nas fontes hispano-visigodas: aspectos teóricos. In: Anais da XXI Reunião da Sociedade Brasileira de Pesquisa Histórica. Curitiba, p. 81 - 96, 2002.

O problema da legitimidade e a limitação do poder régio na Hispania visigoda: o reinado de Ervígio ( 680-687). Gerión, Madrid, v. 22, n. 1.p. $421-435,2004$.

Cultura e Poder na Antigüidade Tardia Ocidental. São Paulo: ABDR, 2000.

GARCIA MORENO, Luis A. Historia de España Visigoda. Madrid: Cátedra, 1989.

LYNCH, C. H. e GALINDO, P. San Braulio O bispo de Zaragoza (631 651): Su vida y sus obras. Madrid: Instituto Enrique Florez, 1950.

ORLANDIS, J. História Del Reino Visigodo Español. Madrid: Rialp, 1990.

RAINHA, R. S. A Educação no Reino Visigodo: as relaçôes de poder e o epistolário do bispo Bráulio de Saragoça. Rio de Janeiro: HP Comunicações, 2007.

SANTIAGO CASTELLANOS. La Hagiografia Visigoda. Dominio social y proycción cultural. Logroño: Fundación San Millán de la Cogolla, 2004. p. $163-302$.

THOMPSON, E. A. Los Godos en España. Madrid: Alianza, 1971. p. $299-342$.

VELASQUEZ SORIANO, Isabel. Âmbitos y ambientes de la cultura escrita em Hispania (s. VI): De Martín de Braga a Leandro de Sevilla. Studia Ephemeridis Augustinianum, Roma, n. 46, p. 329 - 351, 1994. 